DOI: $10.20472 / E S .2015 .4 .2 .001$

\title{
THE NET STABLE FUNDING RATIO OF US BANK HOLDING COMPANIES: A RETROSPECTIVE ANALYSIS
}

\author{
PETROS ARVANITIS, KONSTANTINOS DRAKOS
}

\begin{abstract}
:
We calculate the Net Stable Funding Ratio (NSFR) for US Bank Holding Companies between 2001-2013. We find, that for the vast majority of cases the NSFR was compatible with the Basel III threshold. In addition, we document a significant deterioration of about $10 \%$ of the NSFR during the post-financial crisis period. Moreover, the NSFR exhibits significant heterogeneity across size segments, with its mean level dropping at a decreasing rate.The Net Stable Funding Ratio (NSFR hereafter) is a structural micro-prudential metric of maturity transformation risk, introduced by the Basel Committee of Bank Supervision (BCBS hereafter) in its Basel III accord (BIS, 2010; Gobat et al., 2014).
\end{abstract}

\section{Keywords:}

Bank Holding Companies, Net Stable Funding Ratio, US

JEL Classification: G21, G28, G32

\section{Authors:}

PETROS ARVANITIS, Athens University of Economics and Business, Greece, Email: KONSTANTINOS DRAKOS, Athens University of Economics and Business, Greece, Email: kdrakos@aueb.gr

\section{Citation:}

PETROS ARVANITIS, KONSTANTINOS DRAKOS (2015). The Net Stable Funding Ratio of US Bank Holding Companies: A Retrospective Analysis . International Journal of Economic Sciences, Vol. IV(2), pp. 1-9., 10.20472/ES.2015.4.2.001 


\section{Introduction}

The Net Stable Funding Ratio (NSFR hereafter) is a structural micro-prudential metric of maturity transformation risk, introduced by the Basel Committee of Bank Supervision (BCBS hereafter) in its Basel III accord (BIS, 2010; Gobat et al., 2014). It is based on the recognition that bank's management incentives to limit excessive reliance on unstable short-term funding are feeble. It is intended to capture the banks' assets proportion considered to be less liquid, like long-term loans with maturity over one year, funded by short-term funding of less than one year, or less reliable and stable funding sources. Essentially it is a measure of bank capital stability indicating that bank's liquidity is sufficient to ensure at least one year survival in a stress scenario (De Waal et al., 2013). In other words, the NSFR is a structural ratio which is designed to address liquidity mismatches and provides incentives for banks to use stable sources to fund their activities.

The NSFR is expected to go into full effect by January 2018 aiming at banks reducing maturity transformation risk by holding more stable and long-term funding sources against less liquid assets (Arregui et al., 2013). Despite its apparent advantages, NSFR has been met with skepticism by the industry for various reasons, such as its intrusive nature in traditional bank role in liquidity and maturity transformation, its effect on intensifying bank competition for scarce deposits, the exacerbation of funding towards shadow banking, the destabilizing abstention of banks with large maturity transformation gap from long-term financing and the disproportional effect on emerging and developing countries' economy whose capital markets are undeveloped and its long-term funding relies mostly on banks (Gobat et al., 2014, Hong; 2013). Part of the above concerns are fueled by the lack of familiarity with the NSFR since it's a newly introduced micro prudential measure whose calculation is rather complicated and mechanistic, compared to other structural measures of maturity transformation risk.

Most of the NSFR related studies so far, such as the Quantitative Impact Studies (QIS) conducted by the BCBS (2012a, 2012b, 2013a, 2014b), the monitoring exercises of the European Banking Authority (2014) and the studies by Giordana and Schumacher (2011), De Waal et al. (2013), King (2013), Gobat et al. (2014), and Hong et al. (2014) either cover a limited portion of the banking system or examine the NSFR for a limited period.

The present study has three aims. The first is to calculate the newly introduced NSFR for the population of the US Bank Holding Companies (hereafter BHCs), using the NSFR revised weights presented by the BCBS in January 2014. By doing so we contribute to the scant literature and we also provide insights for a major banking sector such as the US. The second is to calculate the NSFR for a time period, not only covering the post-introduction period, but also extending the analysis as far back as 2001. Such a time window encompasses the relatively calm period prior to 2007, as well as, the recent financial crisis, and therefore lends itself for exploring the naturally arising question of how the NSFR behaved during the crisis. The third is to investigate any potential differences in the NSFR across different size segments of BHC. Size is a 
fundamental bank characteristic, known to account for observed cross-sectional differences on several bank facets (Gorton and Rosen, 1995, Demsetz et al., 1997, Bhagat et al., 2012)

The empirical analysis that will follow is relatively simple, essentially utilizing t-statistics that will assist us in uncovering potential statistical differences. In a sense we present a mere statistical analysis of data properties in order to gauge date properties and for the time being abstain from conducting econometric analysis.

\section{Data sources and variables' definitions}

We employ data for all USA Bank Holding Companies collected from the FR Y-9C report, the Consolidated Financial Statement for BHCs reports compiled by the Federal Bank of Chicago. Our sample consists of 2,804 BHCs and tracked annually for the period 2001-2013, creating an unbalanced panel of 18,578 bank-year observations.

\subsection{NSFR Construction}

The NSFR is defined as the bank's available stable funding (ASF hereafter) divided by its required stable funding (RSF hereafter), with banks having to meet the minimum regulatory ratio of 100 percent, or 1 in the form of ratio (the form we will be using in the remainder of this paper) in the beginning of 2018. The weights assigned to each liability and asset upon their inclusion in the ASF and RSF indicators, range from $0 \%$ to $100 \%$ reflecting: (i) for liabilities their stability as sources of funding and (ii) for assets their illiquidity. Therefore a more stable funding source has a higher ASF weight than a less stable one. Similarly more illiquid assets are given higher RSF weights than more liquid ones, which enjoy lower weights.

The construction was based on the revised weights according to the Basel III liquidity framework issued in January 2014. Due to the lack of granular liquidity risk reporting across BHCs, in order to create the NSFR variable we need to make some assumptions according to the methodology proposed by Gobat et al. (2014), presented in Table 1.

Table 1. Summary of weights assigned to assets and liabilities in NSFR calculations

\begin{tabular}{|c|c|c|c|c|c|}
\hline \multicolumn{3}{|c|}{ ASF } & \multicolumn{3}{|c|}{ RSF } \\
\hline \multicolumn{2}{|c|}{ Liability } & $\begin{array}{c}\text { ASF } \\
\text { Weight }\end{array}$ & & Asset & $\begin{array}{c}\text { RSF } \\
\text { Weight }\end{array}$ \\
\hline \multirow{3}{*}{ Deposits } & Current & $95 \%$ & \multirow{3}{*}{ Loans } & $\begin{array}{c}\text { Residential and } \\
\text { other mortgage } \\
\text { loans }\end{array}$ & $85 \%$ \\
\hline & Savings & $90 \%$ & & $\begin{array}{c}\text { Consumer retail } \\
\text { loans }\end{array}$ & $85 \%$ \\
\hline & Term & $90 \%$ & & $\begin{array}{c}\text { Corporate and } \\
\text { commercial loans }\end{array}$ & $85 \%$ \\
\hline
\end{tabular}




\begin{tabular}{|c|c|c|c|c|}
\hline $\begin{array}{l}\text { Deposits from } \\
\text { banks }\end{array}$ & $0 \%$ & & $\begin{array}{l}\text { ans and } \\
\text { ances to } \\
\text { janks }\end{array}$ & $0 \%$ \\
\hline \multirow{2}{*}{ Short term borrowing } & \multirow{2}{*}{$50 \%$} & \multirow{2}{*}{ Securities } & Level 1 & $5 \%$ \\
\hline & & & Level 2 & $50 \%$ \\
\hline Long term borrowing & $100 \%$ & \multicolumn{2}{|c|}{$\begin{array}{c}\text { At-equity investments in } \\
\text { associates }\end{array}$} & $100 \%$ \\
\hline \multirow{2}{*}{$\begin{array}{l}\text { Trading and other } \\
\text { liabilities }\end{array}$} & \multirow{2}{*}{$0 \%$} & \multirow{2}{*}{$\begin{array}{c}\text { Net } \\
\text { derivatives }\end{array}$} & Positive & $100 \%$ \\
\hline & & & Negative & $0 \%$ \\
\hline \multirow{4}{*}{ Equity } & \multirow{4}{*}{$100 \%$} & \multicolumn{2}{|c|}{ Other earning assets } & $100 \%$ \\
\hline & & \multicolumn{2}{|c|}{$\begin{array}{c}\text { Non-interest earning } \\
\text { assets }\end{array}$} & $100 \%$ \\
\hline & & \multicolumn{2}{|c|}{ Cash } & $0 \%$ \\
\hline & & \multicolumn{2}{|c|}{ Off-balance sheet } & $5 \%$ \\
\hline
\end{tabular}

Notes: The assumptions we need to make according to the methodology proposed by Gobat et al. (2014) are the following: (a) Loans are treated conservatively being given an $85 \%$ weight in RSF assuming that they all have a maturity of more than 1 year., (b) Since BHC's financial statements do not provide details on assets that are encumbered and unencumbered, nor a detailed breakdown of HQLAs such as Level 1, Level 2a and Level 2b assets consistent with the LCR framework, we weight the holdings of government securities by $5 \%$ consistent with the revised Basel III NSFR, and all other securities by $50 \%$, (c) Customer deposits were differentiated between current, term, and savings deposits, (d) derivatives were treated on a net basis and assigned $100 \%$ weight if there was a positive net balance, and $0 \%$ otherwise, (e) and hybrid instruments that have debtlike features were treated as long-term funding instruments.

\section{3.}

\subsection{NSFR sample properties}

Panel A of Table 2 reports the summary statistics of the calculated NSFR. Our sample has a total of $18,576 \mathrm{BHC}$-year observations, with only 307 of them being below the supervisory threshold of 1 , therefore $98 \%$ of the sample observations are above the supervisory threshold. The average of NSFR is 1.40 , while its median attains a value of 1.35. It is also interesting to note that the first quartile is at the level of 1.24, while the third quartile 1.49. The descriptive statistics of the NSFR we come up with are in line with those of the QIS reported in September 2014where the 78\% of the banks were above the supervisory threshold of 1 are and the $88 \%$ of the banks have NSFR above 0.9 . 
Table 2. NSFR descriptive statistics

In Panel B of Table 2 we report the sample properties for the pre and post crisis

\begin{tabular}{|c|c|c|c|c|c|c|c|c|c|c|}
\hline Year & Mean & St. Dev. & Min & $\begin{array}{c}\text { 25th } \\
\text { percentile }\end{array}$ & Median & $\begin{array}{c}\text { 75th } \\
\text { percentile }\end{array}$ & $\operatorname{Max}$ & Obs. & Skewness & Kurtosis \\
\hline \multicolumn{11}{|c|}{ Panel A } \\
\hline All Years & 1.401 & 0.385 & 0.22 & 1.24 & 1.35 & 1.49 & 25.83 & 18576 & 26.46 & 1451.08 \\
\hline 2001 & 1.456 & 0.392 & 0.22 & 1.3 & 1.4 & 1.55 & 13.39 & 1874 & 16.18 & 464.04 \\
\hline 2002 & 1.476 & 0.586 & 0.23 & 1.3 & 1.4 & 1.57 & 22.78 & 2009 & 25.35 & 883.31 \\
\hline 2003 & 1.479 & 0.624 & 0.23 & 1.29 & 1.4 & 1.57 & 25.83 & 2158 & 28.30 & 1082.88 \\
\hline 2004 & 1.436 & 0.324 & 0.24 & 1.26 & 1.37 & 1.53 & 6.7 & 2258 & 4.59 & 52.32 \\
\hline 2005 & 1.442 & 0.306 & 0.27 & 1.28 & 1.38 & 1.54 & 6.28 & 2270 & 4.71 & 53.47 \\
\hline 2006 & 1.364 & 0.222 & 0.28 & 1.24 & 1.33 & 1.45 & 3.25 & 986 & 2.03 & 15.21 \\
\hline 2007 & 1.323 & 0.236 & 0.23 & 1.21 & 1.29 & 1.4 & 3.67 & 966 & 3.28 & 29.97 \\
\hline 2008 & 1.267 & 0.222 & 0.25 & 1.15 & 1.25 & 1.35 & 3.74 & 973 & 3.05 & 32.31 \\
\hline 2009 & 1.281 & 0.215 & 0.31 & 1.17 & 1.27 & 1.38 & 3.73 & 1015 & 1.89 & 21.99 \\
\hline 2010 & 1.308 & 0.226 & 0.35 & 1.18 & 1.28 & 1.4 & 3.67 & 1009 & 2.31 & 20.54 \\
\hline 2011 & 1.340 & 0.216 & 0.34 & 1.21 & 1.31 & 1.43 & 3.03 & 1018 & 1.64 & 11.78 \\
\hline 2012 & 1.360 & 0.230 & 0.69 & 1.22 & 1.32 & 1.45 & 3.64 & 1015 & 2.55 & 19.59 \\
\hline 2013 & 1.360 & 0.214 & 0.69 & 1.23 & 1.32 & 1.44 & 2.86 & 1025 & 1.89 & 10.74 \\
\hline
\end{tabular}

period. Based on point estimates there seems to be a difference of almost 13 basis points, or the post-crisis mean exhibits a $10 \%$ drop relatively to its pre-crisis level. In addition, we report the NSFR across BHC size classes (based on sample asset quartiles) and find a pattern potentially compatible with a decrease of NSFR with BHC size. The decrease between the micro and the small BHC segment is about $7.5 \%$, the corresponding decrease between small and medium segment is $3.5 \%$ and finally the drop between medium and large is about $2.8 \%$. Thus the drop across size segments appears to be taking place at a decreasing rate. 
Panel B

\begin{tabular}{l|cccccccccc}
\hline $\begin{array}{c}\text { Pre }- \\
\text { Crisis }\end{array}$ & 1.449 & 0.448 & 0.22 & 1.28 & 1.39 & 1.54 & 25.83 & 11555 & 26.51 & 1256.13 \\
$\begin{array}{c}\text { Post }- \\
\text { Crisis }\end{array}$ & 1.320 & 0.225 & 0.23 & 1.20 & 1.29 & 1.41 & 3.74 & 7021 & 2.33 & 20.65 \\
\hline Micro & 1.513 & 0.345 & 0.69 & 1.32 & 1.44 & 1.62 & 6.70 & 4644 & 4.39 & 43.50 \\
Small & 1.407 & 0.262 & 0.58 & 1.26 & 1.36 & 1.50 & 9.03 & 4644 & 6.78 & 162.50 \\
Medium & 1.360 & 0.219 & 0.36 & 1.23 & 1.32 & 1.45 & 3.47 & 4644 & 2.22 & 15.72 \\
Large & 1.322 & 0.580 & 0.22 & 1.19 & 1.28 & 1.39 & 25.83 & 4644 & 29.55 & 1131.92 \\
\hline
\end{tabular}

\section{Assessing time and size differences in NSFR}

\section{1. $\quad \quad \quad$ NSFR behavior during the pre and post crisis periods}

Motivated by the preliminary finding discussed in the previous section we proceed with a statistical investigation. In particular in order to examine whether there is any significant difference in the NSFR behavior we conduct appropriate versions of $\mathrm{t}$ statistics reported in Table 3. First we report the standard t-test $(\tau)$ and then in order to account for the correlated samples' nature of our dataset, we also use two alternative corrected versions:

$$
\begin{aligned}
\tau^{\prime} & =\frac{\bar{D}}{\sqrt{\frac{\Sigma D^{2}-\frac{(\Sigma D)^{2}}{n}}{n(n-1)}}} \\
\tau^{\prime} & =\frac{\tau}{\sqrt{1-\rho}}
\end{aligned}
$$

where $D$ is the pre-post difference in NSFR means, $\bar{D}$ is the mean of the difference, $\rho$ is the correlation between the pre and post and $n$ is the sample size.

According to the results obtained from the corrected t-tests for the comparison of the pre-crisis and the post-crisis periods we emphatically reject the null hypothesis for the equality of means between these two periods. In particular we confirm that there is, as expected, a statistically significant drop in NSFR means in the post crisis period.

These results are compatible with conventional wisdom indicating that the liquidity reserves during and after the financial crisis should be lower than those of the pre-crisis period. This could be explained by the notion that BHCs in the post crisis period used a part of their liquid reserves in order to cover their funding needs rose by the financial 
crisis as well as by the fact that the liquidity creation abilities of the BHCs during the financial crisis were diminished.

Table 3. NSFR t-tests. The first t-test correction method is using the $\tau^{\prime}=\frac{\bar{D}}{\sqrt{\frac{\Sigma D^{2}-\frac{(\Sigma D)^{2}}{n}}{n(n-1)}}}$ formula, and the second is using the $\tau^{\prime}=\frac{\tau}{\sqrt{1-\rho}}$ formula, where $\tau$ is the original t-test, $D$ is the yearly difference, $\rho$ is the yearly correlation and $n$ is the years' population.

\begin{tabular}{|c|c|c|c|}
\hline \multicolumn{4}{|c|}{ Panel A } \\
\hline Corrected t-test by period & Original t-test & $\begin{array}{c}\text { First correction } \\
\text { method }\end{array}$ & Second correction method \\
\hline Pre - Post Crisis & 26.02 & 23.76 & 25.81 \\
\hline
\end{tabular}

\subsection{NSFR behavior by BHC size}

We perform the same tests with respect to $\mathrm{BHC}$ size. According to the results obtained from the corrected t-tests for all three pairs (micro vs. small, small vs. medium and medium vs. large) we emphatically reject the null hypothesis for the equality of means between size classes. In particular we confirm that there is a statistically significant drop in NSFR means as BHC size increases. The above results are compatible with the Basel Committee's December 2013 QIS findings of more banks over the regulatory threshold for the smaller banks group as well as in Hong et al. (2013) where large banks appear to have significantly lower NSFR than the small and mid-sized banks.

These findings could be explained in light of the different effects taking place in different size BHCs. For larger banks the risk absorption effect prevails indicating that they are able to bear riskier portfolios of potentially more lucrative illiquid assets, such as commercial loans and loan commitments, rather than safer liquid investments such as treasury bonds. Another possibility is the too-big-to-fail theory, according to which larger $\mathrm{BHCs}$ take for granted a bail out and therefore are more reckless in terms of risk-taking. In contrast, smaller banks are according to the financial fragility theory (Diamond and Rajan, 2000, 2001) due to their narrower capital base are compelled to retain more liquid assets in order to gain trust by their depositors. 


\begin{tabular}{|c|c|c|c|}
\hline \multicolumn{4}{|c|}{ Panel B } \\
\hline Corrected t-test by size & Original t-test & $\begin{array}{c}\text { First correction } \\
\text { method }\end{array}$ & Second correction method \\
\hline Micro - Small & 16.63 & 16.51 & 16.66 \\
\hline Micro - Medium & 25.55 & 25.97 & 26.12 \\
\hline Micro - Large & 19.30 & 19.36 & 19.41 \\
\hline Small - Medium & 9.47 & 9.42 & 9.54 \\
\hline Small - Large & 9.13 & 9.04 & 9.07 \\
\hline Medium - Large & 4.14 & 4.05 & 4.13 \\
\hline
\end{tabular}

\section{Conclusions}

As a result of the recent financial crisis and the subsequent numerous failures of banking institutions, that highlighted the Basel II stability indicators' vulnerability, international banking authorities introduced among others the NSFR micro-prudential measure as a way to address these issues in the future.

In this study we calculate the NSFR metric for the US BHC during the period 2001-2013 in order to assess retrospectively whether banks satisfied the suggested criterion. Moreover we investigated potential differences between the pre and post crisis periods as well as across size trenches.

According to our findings during the time period under analysis, US BHCs' Net Stable Funding Ratio is found to satisfy the BCBS threshold. In addition we document, as expected, a significant deterioration of about $10 \%$ of the NSFR during the post-crisis period. The NSFR also exhibits significant heterogeneity across size segments, with its mean level dropping at a decreasing rate.

The policy recommendations emerging from our analysis are the following. Primarily authorities should take into account the dependence of the NSFR to bank size, since the fact that the NSFR drops with size might imply that potential liquidity hazards are lurking. Moreover, the significant deterioration of the NSFR during the post-crisis period indicates its increased sensitivity to market conditions. Further research could explore whether it behaves pro or counter-cyclically.

\section{References}

Arregui, M. N., Norat, M. M., Pancorbo, A., Scarlata, J. G., Holttinen, E., Melo, F. \& Yanase, M. (2013). Addressing Interconnectedness: Concepts and Prudential Tools (No. 13-199). International Monetary Fund.

Bank of International Settlements, 2010, Basel III: International framework for liquidity risk measurement, standards and monitoring. Consultative Document.

Basel Committee of Banking Supervision, 2012a, Results of the Basel III monitoring exercise as of 30 June 2011

Basel Committee of Banking Supervision, 2012b, Results of the Basel III monitoring exercise as of 31 December 2011 
Basel Committee of Banking Supervision, 2013a, Results of the Basel III monitoring exercise as of 30 June 2012.

Basel Committee of Banking Supervision, 2014b, Results of the Basel III monitoring exercise as of 31 December 2014.

Bhagat, S., Bolton, B. J., Lu, J., 2012. Size, Leverage, and Risk-Taking of Financial Institutions, Working paper.

De Waal, B., Petersen, M. A., Hlatshwayo, L. N., \& Mukuddem-Petersen, J. (2013). A note on Basel III and liquidity. Applied Economics Letters, 20(8), 777-780.

Demsetz, R.S., Saidenberg, M.R., Strahan, P.E., 1997. Agency Problems and Risk Taking at Banks. Staff Reports, No. 29. Federal Reserve Bank of New York.

European Banking Authority, 2014, Basel III monitoring exercise, results based on data as of 31 December 2013

Giordana, G., \& Schumacher, I. (2011). The impact of the Basel III liquidity regulations on the bank lending channel: A Luxembourg case study (No. 61). Central Bank of Luxembourg.

Gobat, J., Yanase, M., \& Maloney, J. F. (2014). The Net Stable Funding Ratio: Impact and Issues for Consideration.

Gorton, G., Rosen, R., 1995. Corporate control, portfolio choice, and the decline of banking. Journal of Finance 50, 1377-1420.

Hong, H., Huang, J. Z., \& Wu, D. (2014). The information content of Basel III liquidity risk measures. Journal of Financial Stability, 15, 91-111.

King, M. R. (2013). The Basel III net stable funding ratio and bank net interest margins. Journal of Banking \& Finance, 37(11), 4144-4156. 